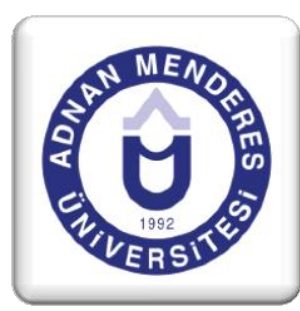

\title{
Giresun'daki Fındık Fabrikalarının Etkinlik Analizi: Malmquist - TFV Endeksi Uygulaması
}

\section{Efficiency Analysis Of The Hazelnut Factories In The City Of Giresun \\ The Application of Malmquist - TFP Index}

\author{
Hatice DOĞAN ${ }^{1}$, Yetkin BULUT ${ }^{2}$
}

\section{Özet}

Bu çalışmanın amacı 2006-2012 dönemi için Giresun'daki fındık fabrikalarının performanslarını incelemektir. Belirlenen dönemler için her bir fabrikanın Toplam Faktör Verimliliğindeki değişim, Malmquist- Toplam Faktör Verimliliği Endeksi yöntemi kullanılarak incelenmiştir. Elde edilen sonuçlara göre 2006-2012 yılları arasında fabrikaların toplam faktör verimliliğinde azalma olduğu görülmüştür. Bu azalış hem teknik etkinlikteki değişimden hem de teknolojik değişimden kaynaklandığı tespit edilmiştir.

Anahtar Kelimeler: Fındık Fabrikaları, Etkinlik Analizi, Malmquist- Toplam Faktör Verimliliği Endeksi

\section{Abstract}

The purpose of this study is to analyse the performances of the hazelnut factories in Giresun within the period of 2006-2012. For the indicated period, the change within the Total Factor Productivity was analyzed by using Malmquist- Total Factor Productivity Index method. According to the obtained results, it was observed that there was a decrease in the Total Factor Productivity of the factories between the years 2006-2012.

\footnotetext{
${ }^{1}$ Öğretim görevlisi, Giresun Üniversitesi Sosyal Bilimler Meslek Yüksekokulu, hatice.dogan@giresun.edu.tr, Giresun

${ }^{2}$ Yard. Doç. Dr., Ondokuz Mayıs Üniversitesi İktisadi ve İdari Bilimler Fakültesi, yetkin.bulut@ hotmail.com, Samsun
} 
It was determined that this decrease resulted from both transformation at technical efficiency and technological transformation.

Keywords: Hazelnut Factories, Efficiency Analysis, Malmquist- Total Factor Productivity Index

\section{Giriş}

Günümüzde teknolojik alanda yaşanan büyük çaptaki gelişmeler ve değişimler tarım sektöründe de etkisini göstermiştir. Tarım sektöründeki verimliliği artırabilmek için gelişen teknoloji kullanmak gerekmektedir. Türkiye'de tarım, hem ekonomiye katkısı hem de istihdam alanı olması bakımından büyük önem taşımaktadır. Türkiye'de tarım sektörü içerisinde fındık önemli bir paya sahiptir.

2011 yılında dünyada yaklaşık 904 bin hektar (ha) alanda findık yetiştirildiği tahmin edilmektedir. Türkiye tek başına dünya findık alanının 697 bin hektar alanına sahiptir. Dünyadaki fındık ekim alanlarının yaklaşık \% 77'si Türkiye'de bulunmaktadır. İtalya \% 8'lik payla ikinci sırada yer almaktadır. Diğer ülkeler arasında sirasıyla Gürcistan, Azerbaycan, ispanya ve ABD izlemektedir. International Nut Council (2012) raporuna göre 2005-2012 y1lları arasında dünya findık ihracatı ortalamas1 842 bin ton (kabuklu findık cinsinden) olup, bunun yaklaşık \%70'i Türkiye gerçekleştirmiştir. Dünyada fındık tüketiminin neredeyse tamamına yakını (\%91), Avrupa Birliği ve diğer Avrupa ülkeleri tarafından gerçekleştirilmekte ve büyük ölçüde (\%80'i) çikolata ve şekerleme sanayinde hammadde olarak kullanılmaktadır (Gümrük ve Ticaret Bakanlığ 1 Kooperatifçilik Genel Müdürlügü 2012 Yılı Findık raporu, 2013).

Türkiye'nin tarımsal yapısı çoğunlukla kendi arazisini işleyen, sermayesi yetersiz, eğitim ve teknoloji bakımından yetersiz, uygun olmayan büyüklükte faaliyet gösteren bir yapıya sahiptir. Devletin fındığa 1964 yılından bu yana maliyetlerin üzerinde fiyatlardan alım garantisi vermesi, fındığın diğer ürünlere göre nispeten az emekle yetiştirilen bir ürün olması, bölgeden yapılan göçler vb. etkenlerden dolayı önce Batı Karadeniz Bölgesi, daha sonra ise diğer bölgelere yayılmıştır. Türkiye'nin 1970'li yıllarda 260 bin ton civarında olan fındık üretimi 2008 y1lında 801 bin ton, 2009 yılında 500 bin ton, 2010 yılda 600 bin ton ve 2011 y1lında ise yaklaşık 430 bin ton olarak gerçekleşmiştir (TÜiK, 2011).

Ülkemizde yaşanan ekonomik krizlerden dolayı kuruluşların kaynaklarının kullanımını ve performansın geliştirilmesi için yapılan çalışmaları arttırmıştır. İşletmelerin göstermiş oldukları iyi veya kötü performansı belirlemek diğer bir deyişle etkin ve etkin olmayan işletmeleri birbirlerinden ayırt etmek gerekmektedir. Etkin olmayan işletmeleri belirlemek ve bu etkinsizliğin nedenini tespit edebilmek için de kullanılan tekniklerden biri de Veri Zarflama Analizi (VZA) dır.

VZA, temel olarak belirli bir çıktı düzeyinin minimum girdi miktarıyla elde edilmesini amaçlayan girdi yönelimli model ve belirli bir girdi düzeyi ile maksimum çıktının sağlanmasını amaçlayan çıktı yönelimli model olmak üzere iki yönlü uygulanabilen bir matematiksel programlama tekniğidir. VZA, uygulandığı birimlerin etkinliğini yalnızca bir dönem için ölçebilen statik bir kesit analizidir. Başka bir deyişle VZA, birimlerin etkinliğinin zaman içinde nasıl değiştiğini 
ölçememektedir. Malmquist-Toplam Faktör Verimliliği Endeksi (MTFVE), karar verme birimlerinin (KVB) ortak bir teknolojiye göre her bir veri noktasının uzaklıklarının oranlarını hesaplayarak, farklı zamana ait iki veri noktası arasındaki toplam faktör verimliliğindeki (TFV) değişimi ölçen ve yaygın olarak kullanılan bir tekniktir (Lorcu, 2010: 279).

Bu çalışmanın amacı, Giresun'daki fındık fabrikalarının göreli etkinliklerinin 2006-2012 yılları arasında nasıl değişim gösterdiğini Malmquist- Toplam Faktör Verimliliği endeks ile ölçmektir. Aynı zamanda yapılan ölçüm sonrasında meydana gelen değişimin nelerden kaynaklandığını da ortaya koymaktır. 2013 yılına ait veriler henüz hazırlanmadığından çalışmaya dahil edilememiştir.

Çalışma, altı ana başlık altında toplanmıştır. İkinci bölümde, tarım sektöründe yapılan Malmquist-TFV endeksi çalışmalarını içeren literatür araştırmasına yer verilmiştir. Üçüncü bölümde, Malmquist-TFV Endeksi yöntemine ait teorik bilgiler anlatılmıştır. Dördüncü bölümde, uygulama aşamasında kullanılacak veriler ve değişkenler anlatılmıştır. Beşinci bölümde, analiz sonuçları ortaya konulmuş, altıncı ve son bölümde ise sonuçlar değerlendirilerek önerilerde bulunulmuştur.

\section{Literatür Araștırması}

Malmquist-Toplam Faktör Verimliliği Endeksi’nin başlıca uygulama alanları, bankalar (Cingi ve Tarım, 2000; Öncü ve Aktaş, 2007; Dağ, 2011), hastaneler (Aktan ve Tosun, 2010; Şahin, 2009; Sülkü, 2011), özel sektör imalat sanayi (Zaim ve Taşkın, 1997; Arcelus ve Arozena, 1999; Deliktaş, 2002; Chen, 2003; Kesbiç ve diğerleri, 2004; Kayal1, 2007; Perçin ve Ustasüleyman, 2007; Dinçer, 2008; Kula ve diğerleri, 2009; Lorcu, 2010), kamu kuruluşları (Demirci, 2001; Kutlar ve diğerleri, 2010; Çakır, 2011), üniversiteler (Küçükşimşek, 2004), tarım (Coelli ve Rao, 2003; Raheman ve diğerleri, 2009; Demirci, 2003; Candemir ve Deliktaş, 2006; Sevim, 2006; Özok, 2006; Bozbăg, 2007; Avcı ve Kaya, 2008; Ar ve Baki, 2009; Mollavelioğlu, 2009; Kılıç ve diğerleri, 2009; Candemir ve diğerleri, 2011) yer almaktadır.

Tarım sektörüne yönelik yapılmış ve etkinlik karşılaştırmasını içeren çalışmalara yer verilen bu bölümde ilk olarak Dünya'daki tarım sektörüne yönelik uygulamalar ortaya konulmuştur. $\mathrm{Bu}$ çalışmaların ilkinde Coelli ve Rao (2003), 1980-2000 yılları arasında 93 ülkede tarımdaki verimlilik değişimini Malmquist-TFV endeksi yardımıyla ölçmüştür. Tarımda verimlilikteki gelişmeleri yakalamak ya da bazı durumlarda olası uyuşmazlık konuları global çerçevede ele alıp incelenmiştir. Raheman ve diğerleri (2009) tarafindan, Pakistan' da faaliyet gösteren ve Karaçi Borsası'na kote olmuş 20 adet şeker fabrikası üzerine yapılan çalışmada ise fabrikaların 1998-2007 yılları arasındaki TFV değişimi MTFVE yöntemiyle ölçülmüştür. Sonuç olarak, söz konusu fabrikalarda TFV endeksinde toplamda \% 0,1'lik bir azalma tespit edilmiştir.

Dünyada yapılan bu çalışmalara ek olarak Türkiye'deki kuruluşlara yönelik olarak da Malmquist-TFV endeksi ölçümü yapılmıştır. Demirci (2003) tarafından, 18 adet TŞFAŞ (kamu), 2 adet karma (TŞFAŞ ve PANKOBİRLIKK) ve 3 adet özel (PANKOBİRLIKK) olmak üzere toplam 23 Şeker fabrikasında, 1987-1999 yıllarını kapsayan 13 yıllık dönem için VZA ile etkinlik ölçümü yapılmıştır. Sonuç olarak, fabrikaların büyük bir kısmının zaman içinde teknik etkinliği yakaladığı görülmüştür. Candemir ve Deliktaş (2006), 1999-2003 arasındaki dört yıllık dönem için Tarım İşletmeleri Genel Müdürlüğ̈’ne (TİGEM) bağlı devlet üreme çiftliklerinin üretim performanslarını ve toplam faktör verimliliklerindeki değişimini incelemiş̧ir. Araştırma sonucunda, 1999-2003 döneminde devlet üretme çiftliklerinin toplam faktör verimliliğinde yıllık ortalama \%3,3 artış olduğu görülmüştür. $\mathrm{Bu}$ artışın teknolojik ilerlemeden kaynaklandığı saptanmıştır. Sevim (2006), Avrupa Birliği ve aday 28 ülkenin 1993-2002 dönemi için tarımsal etkinliklerini Malmquist-TFV endeksi ile incelemiştir. Çalışmanın sonucunda toplam faktör verimlilik endeksinde \%0,9 oranında bir azalma olduğu görülmüştür. Özok (2006), 1998-2003 yılları için Türkiye'deki İllerin Tarım Etkinliklerinin incelenmesinde VZA ve Malmquist-TFV endeksi yöntemiyle incelemiştir. Sonuç olarak toplam faktör verimliliğinin $\% 0,70$ oranında bir artış gösterdiğinin bu artışın $\% 1$ teknik değişimdeki artıştan, \%0,3 etkinlik değişimi azalışından olduğu saptanmıştır. Bozdağ (2007) tarafından, TŞFAŞ ve özel şeker 
fabrikalarının tümünde ve AB ülkelerinde VZA ile 1990-2005 dönemi için etkinlik ölçümü yapılmış ve her ülkenin üretim etkinlikleri karşılaştırmalı olarak değerlendirilmiştir. Malmquist-TFV endeksi ile de Türkiye ve $A B$ ülkelerinin şeker sanayilerinin üretim etkinliklerindeki değişimi incelenmiştir. Çalışma sonucunda, Türkiye şeker sanayisinin üretim etkinliğinin yüksek olduğu ve $A B$ pazarı içinde üretimde rekabetçi bir yapıya sahip olduğu ortaya konulmuştur. Avcı ve Kaya (2008), 1992-2004 yılları arasında Türkiye ile geçiş ekonomileri olarak adlandırılan ülkelerin tarım sektörü performanslarını VZA ve Malmquist-TFV endeksi yöntemi kullanarak incelemiştir. Çalışmanın sonucunda, geçiş ekonomilerinin ortalama teknik etkinlikteki değişim değeri \%1,6; teknolojik değişim değeri $\% 0,7$ ve toplam faktör verimliliğindeki değişimi $\% 2,3$ olarak belirlenmiştir. Türkiye'nin teknik etkinlikteki değişim değeri diğer ülkelerin ortalaması ile aynı kalırken teknolojik değişim oranı \%0,1 oranında azalmış ve toplam faktör verimliliği \%0,6 oranında artmıştır. Ar ve Baki (2009), 2003-2008 dönemi için Çaykur'a bağlı 44 çay fabrikasının etkinlik analizini yapmış ve belirtilen dönemler içinde Malmquist-TFV endeksi yöntemini kullanarak değerlendirmede bulunmuştur. Sonuçların olumlu yönde değiştiği gözlenmiş ancak teknolojik etkinlik artarken, teknik etkinliğin azaldığı tespit edilmiştir. Mollavelioğlu (2009) 1995-2005 döneminde sürdürülebilir tarımın ölçümü ve Türkiye açısından performansının değerlendirilmesini Malmquist-TVF endeksi yöntemi kullanarak ölçmüştür. Çalışmada toplam faktör verimlilik endeksinde bir atış olduğu bu artışın teknolojik gelişmeden kaynaklandığı tespit edilmiştir. Kılıç, Ceyhan ve Alkan (2009), 2005-2006 yılları için findık bahçelerinin verimliliklerini karşılaştırmayı amaçlamış ve rastgele seçilen 151 bahçe için VZA yöntemini kullanmıştır. Çalışmanın sonucunda etkinsiz çıkan bahçelerin üretim maliyetlerini \%44 oranında azaltması gerektiği tespit edilmiştir. Candemir, Özcan, Güneş ve Deliktaş (2011), Türkiye'nin Fındık Satış Kooperatifleri Birliklerinin 2004-2008 dönemi için etkinlik değişimini Malmquist-TFV endeksi kullanarak incelemiştir. Çalışma sonucuna göre, teknik etkinlik yıllık \%1,3 gelişmiş, teknolojik değişim \%3 azalmış ve Toplam Faktör Verimliliği ise \%1,7 azalmıştır. Çakır (2011), 2002-2009 dönemleri arasında Türkiye Şeker Fabrikaları Anonim Şirketine ait 25 kamu şeker fabrikasının etkinliklerinin zaman içindeki değişimlerini Malmquist-TFV endeksi yöntemiyle incelemiştir. Sonuçta, \%0,6 oranında toplam faktör verimliliği artışı görülmüş ve bu artışın teknolojik gelişim ve etkinlik artışından (sırasıyla \%0,5 ve \%0,1) kaynaklandığı tespit edilmiştir.

$\mathrm{Bu}$ çalışmada, 2006-2012 yılları arasında Giresun'daki findık fabrikalarının performans düzeyleri Malmquist-TFV endeksi kullanılarak hesaplanmıştır. İlk olarak her fabrikanın teknik etkinlikleri belirlenmekte ve sonra toplam faktör verimliliklerindeki değişmeler ölçülmekte ardında ise bu değişmelere neden olan bileşenlerdeki değişme ölçülmektedir. Ayrıca Fındık Fabrikalarının etkinlik analizi ölçümünde Malmquist-Toplam Faktör Verimliliği Endeksi yöntemine rastlanmamıştır.

\section{Yöntem}

Fındık fabrikalarının etkinlik ölçümlerini yapmak için kullanılacak VZA ve Malmquist-TFV endeksi yöntemleri sırasıyla aşağıda açıklanmıştır.

\subsection{Veri Zarflama Analizi}

Veri zarflama analizi, Malmquist-Toplam Faktör Verimliliği Endeksinin hesaplanmasında gerekli olan uzaklık fonksiyonlarının tahmininde kullanılan bir yöntemdir.

VZA, aynı girdileri kullanarak aynı çıktıları üreten homojen karar birimlerinin göreli performansını ölçmeye yönelik olarak kullanılan ve doğrusal programlamayı esas alan parametrik olmayan bir tekniktir. Etkin karar verme birimlerinin oluşturduğu etkin üretim sınırına göre her bir karar biriminin etkinliğini hesaplamaktadır (Ar ve Baki, 2009). Bir karar biriminin göreli etkinliği, o karar biriminin ağırlıklı çıktılarının toplamının ağırlıklı girdilerinin toplamına oranlanmasıdır (Guan, Yam, Mok ve Ma, 2006, 972). Eğer bulunan oran 1 ise karar birimi etkin, 1'den küçükse etkin değildir (Donthu, Hershberge ve Osmonbekov, 2005, 1476).

VZA'da CCR ve BCC modelleri olmak üzere iki temel model yer alır. CCR modeli Charnes, Cooper ve Rhodes (1978) tarafından çıkarılmıştır. Temel varsayımı ölçeğe göre sabit getiri (CRS) 
modelidir. BCR modeli ise Banker, Charnes ve Cooper (1984) tarafindan geliştirilerek ölçeğe göre değişken getiri (VRS) varsayımı esas alınmıştır. Her iki modelde de girdi yönlü ve çıktı yönlü olarak kullanılabilmektedir.

\subsection{Malmquist- Toplam Faktör Verimliliği Endeksi}

Malmquist-TFV endeksi, uzaklık fonksiyonlarına dayalı olarak ifade edilir ve her veri noktasının ortak teknolojiye olan uzaklık oranlarını hesaplayarak, iki veri noktası arasındaki toplam faktör verimliliğindeki değişimi ölçmektedir. Uzaklık fonksiyonu çoklu girdi ve çıktı söz konusu olduğu durumlarda maliyet en küçüklemesi veya kar en büyüklenmesi gibi hedefleri belirtmeden üretim teknolojilerini tanımlamaktadır (Ar ve Baki, 2009: 82). Girdi uzaklık fonksiyonu, çıktı vektörü veri iken oransal olarak en çok büzülen girdi vektörüne bağlı olarak üretim teknolojisini tanımlarken; çıktı uzaklık fonksiyonu, girdi vektörü veri iken oransal olarak en çok genişleyen girdi vektörüne bağlı olarak üretim teknolojisini tanımlar (Tarım, 2001: 152-153). Bu çalışmada uzaklık fonksiyonu girdi eksenli olarak alınmıştır.

Çok sayıda girdi ve çıktı bulunduran üretim teknolojilerini sadece miktar verilerine dayandıran fonksiyonlar uzaklık fonksiyonu olarak adlandırılmaktadır (Fare ve diğerleri, 1994: 68). Shephard (1970) ve Fare (1988) takip edilerek t dönemine ait çıktı uzaklık fonksiyonunu:

$$
D_{0}^{t}\left(x^{t}, y^{t}\right)=\min \left\{\theta:\left(x^{t}, \frac{y^{t}}{\theta}\right) \in S^{t}\right\}
$$

şeklinde ifade edilmiştir. Caves, Christensen ve Diewert (1982, CCD), ölçeğe göre sabit getiri (CRS) olasılığ 1 durumunda herhangi bir $\mathrm{t}$ dönemi ve $\mathrm{t}+1$ dönemi için Malmquist Endeksini:

$$
M_{C C D}^{t}=\frac{D_{0}^{t}\left(x^{t+1}, y^{t+1}\right)}{D_{0}^{t}\left(x^{t}, y^{t}\right)}
$$

şeklinde ifade edilmiştir. Aynı şekilde $\mathrm{t}+1$ dönemi alındığı̆nda:

$$
M_{C C D}^{t+1}=\frac{D_{0}^{t+1}\left(x^{t+1}, y^{t+1}\right)}{D_{0}^{t+1}\left(x^{t}, y^{t}\right)}
$$

şeklinde ifade edilmiştir. CCD tarafindan oluşturulan yukarıdaki (1) ve (2) numaralı eşitliklerin geometrik ortalaması alınarak Malmquist- TFV değişimi indeksi tanımlanmaktadır. Bunlar aşağıdaki gibi ifade edilmiştir (Fare ve diğerleri, 1994: 70):

$$
M_{0}\left(x^{t+1}, y^{t+1}, x^{t}, y^{t}\right)=\sqrt{\left[\left(\frac{D_{0}^{t}\left(x^{t+1}, y^{t+1}\right)}{D_{0}^{t}\left(x^{t}, y^{t}\right)}\right)\left(\frac{D_{0}^{t+1}\left(x^{t+1}, y^{t+1}\right)}{D_{0}^{t+1}\left(x^{t}, y^{t}\right)}\right)\right]}
$$

Yukarıdaki eşitliğin diğer bir yazılış şekli ise aşağıdaki gibidir: 
$\underbrace{M_{0}\left(x^{t+1}, y^{t+1}, x^{t}, y^{t}\right)}_{0}=\underbrace{x}_{\frac{D_{0}^{t+1}\left(x^{t+1}, y^{t+1}\right)}{D_{0}^{t}\left(x^{t}, y^{t}\right)}} \sqrt{\left[\left(\frac{D_{0}^{t}\left(x^{t+1}, y^{t+1}\right)}{D_{0}^{t+1}\left(x^{t+1}, y^{t+1}\right)}\right)\left(\frac{D_{0}^{t}\left(x^{t}, y^{t}\right)}{D_{0}^{t+1}\left(x^{t}, y^{t}\right)}\right)\right]}$

Toplam Faktör Verimliliği Teknik Etkinlik Teknolojik Değişim (TD)

Değişimi (TFVD) Değişimi (TED)

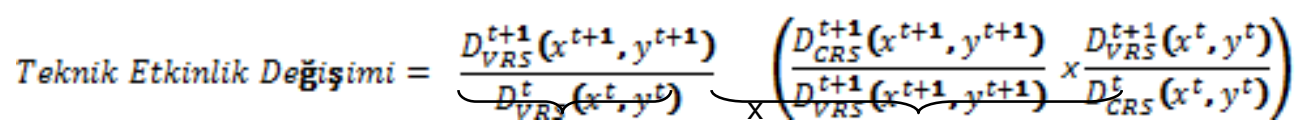

\author{
Saf Teknik Etkinlik $\quad$ Ölçek Etkinliği \\ Değişimi (STED) Değişim (ÖED)
}

(6) numaralı eşitlikte teknik etkinlik değişim, saf teknik etkinlik değişimi ve ölçek etkinlik değişimi olarak ikiye ayrılmıştır. Saf teknik etkinlik değişimi, yönetim uygulamalarındaki gelişmeyi, ölçek etkinliliği değişimi ise maliyet kontrolüne dayalı olarak optimal ölçek büyüklügüundeki gelişmeyi tanımlamaktadır. Dolayısıyla Malmquist-TFV endeksi yaklaşımına göre etkinlikteki değişimin nedeni, yönetim uygulamalarında ya da optimal ölçek büyüklüğündeki iyileşmelerden kaynaklanmaktadır (Isik ve Hassan, 2003: 293).

Teknolojik değişim, etkin sınırın zaman içerisindeki değişimini belirtir. Toplam Faktör Verimliliği Değişimi ise $\mathrm{t}$ dönemden $\mathrm{t}+1$ dönemine kadar toplam faktör verimliliğindeki oluşan değişimi ifade eder.

Malmquist-TFV endeksine ilişkin bu hesaplamaların ardından elde edilen sonuçları değerlendirmek gerekmektedir. Yapılan bu matematiksel işlemler sonucunda bulunan değer üç farklı şekilde ortaya çıkar. Toplam faktör verimliliğindeki değişmeyi gösteren Malmquist-TFV endeksinin;

- $\quad 1$ 'den büyük olması ilgili dönemde bir önceki döneme göre toplam faktör verimliliğinde bir artış olduğunu gösterir.

- 1 'e eşit olması ilgili dönemde bir önceki döneme göre toplam faktör verimliliğinde bir değişme olmadığını gösterir.

- 1 'den küçük olması ilgili dönemde bir önceki döneme göre toplam faktör verimliliğinde bir azalış olduğunu gösterir.

\title{
4. Uygulama
}

Giresun'da 2013 yılı için Bilim, Sanayi ve Teknoloji İl Müdürlüğü kayıtlarına göre 27 fındık fabrikası mevcuttur. Bazı fabrikaların faaliyette olmamas1 ve bazı fabrikaların 2006-2012 yılları arasında üretimde bulunmamasından dolayı etkinlik ölçümü için 13 fındık fabrikası alınmıştır. Araştırmanın güvenilir sonuçlar verebilmesi için girdi ve çıktı sayılarına bağlı olarak karar verme birimleri seçilmelidir. Karar birimi sayısı girdi ve çıktı sayısı toplamının en az iki katı olmalıdır (Boussofiance, Dyson ve Rhodes, 1991) kuralına göre karar biriminin sayısı yeterli olduğu sonucuna varılmıştır.

\subsection{Girdi ve Çıktıların Belirlenmesi}

Girdi ve çıktılar belirlenirken dikkat edilmeli ve önemli bir değişken dışarıda bırakılmamalıdır. Çalışmada bu durum göz önüne alınarak girdi ve çıktılar belirlenmeye çalışılmıştır. 
Buna göre, findık fabrikalarının etkinlik karşılaştırmasında 4 girdi ve 1 çıktıdan oluşan bir girdi seti kullanılmıştır. Çalışmada kullanılan girdi ve çıktı verileri fabrikaların 2006-2012 yılları için işletme cetvellerinden yararlanılarak derlenmiştir. Girdi ve çıktıya ilişkin genel bilgiler aşağıdaki tabloda (Tablo-1) verilmiştir.

\begin{tabular}{|l|l|l|}
\hline \multicolumn{2}{|c|}{ Tablo - 1: Analizde Kullanılan Girdi ve Çıktılar } \\
\hline \multicolumn{1}{|c|}{ Tür } & Birim & \multicolumn{1}{c|}{ Açıklama } \\
\hline Girdi & Acalışan Sayısı & $\begin{array}{l}\text { Her bir fabrika için çalışan mühendis, teknisyen, idari } \\
\text { personel ve işçi sayıları toplanarak elde edilmiştir. }\end{array}$ \\
\hline $\begin{array}{l}\text { Yıllık Makine } \\
\text { Kapasitesi }\end{array}$ & Ton & $\begin{array}{l}\text { Her bir fabrikadaki mevcut makinelerin belirtilen } \\
\text { dönemdeki yıllı üretim kapasitesi dikkate alınarak } \\
\text { hesaplanmıştır. }\end{array}$ \\
\hline Hammadde & Ton & $\begin{array}{l}\text { Her bir fabrikanın ilgili dönemde kullanmak üzere almış } \\
\text { olduğu yıllık kabuklu fındık miktarı dikkate alınarak } \\
\text { hesaplanmıştır. }\end{array}$ \\
\hline Enerji & Kwh & $\begin{array}{l}\text { İlgili dönemde fabrikanın bütün bölümlerinde kullanılan } \\
\text { elektrik enerjisi miktarı toplanarak hesaplanmıştır. }\end{array}$ \\
\hline Çıktı & Ton & $\begin{array}{l}\text { İlgili dönemde her bir fabrikanın ürettiği iç fındık miktarı } \\
\text { toplanarak hesaplanmıştır. }\end{array}$ \\
\hline Üretilen İç Fındık & a \\
\hline
\end{tabular}

Şekil 1: Fındık Fabrikaları Etkinlik Analiz Modeli

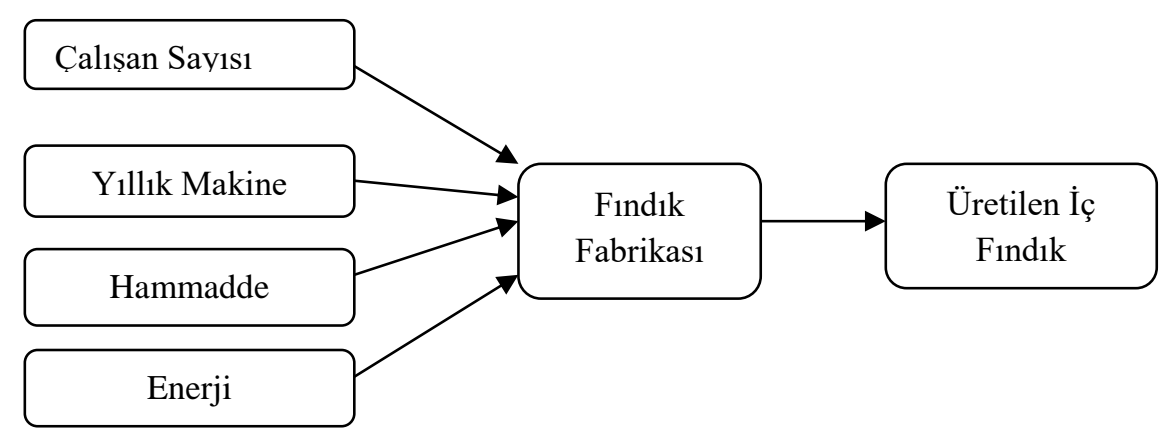

\subsection{Modelin Belirlenmesi}

Malmquist-TFV modelleri girdi ve çıktı yönelimli olarak çözülebilmektedir. Çıktı yönelimli kullanılan modelde amaç belirli bir miktarda girdi ile en fazla çıktıyı belirlemeye yöneliktir. Girdi yönelimli modelde ise belirli bir çıktıyı elde edebilmek için en az girdiyi kullanmayı amaçlar. $\mathrm{Bu}$ araştırmada girdiye yönelik model kullanılmıştır. Burada amaç belirli bir çıktıyı elde edebilmek için elde bulunan girdilerde israfi en aza indirmektir. Malmquist- TFV endeksin verilerinin hesaplanmasında ölçeğe göre sabit getiri (CRS) modeli kullanılmıştır. 


\subsection{Modelin Çözümü}

Bu çalışma kapsamında Giresun'da faaliyette bulunan 13 fındık fabrikasının 2006-2012 yılları arasındaki etkinlik değişimi ve bu değişimin nedenlerini belirlemek amacıyla Malmquist-TFV endeksi değerleri hesaplanmıştır. Verilerin analizinde DEAP 2.1 bilgisayar paket programı kullanılmıştır. Elde edilen sonuçlar Tablo 2 ve Tablo 3 'te verilmiştir.

\begin{tabular}{|c|c|c|c|c|c|}
\hline \multicolumn{7}{|c|}{ Tablo - 2 Fabrikalara Göre Analiz Sonuçları } \\
\hline & $\begin{array}{c}\text { Teknik } \\
\text { Etkinlik } \\
\text { Değişimi } \\
\text { (TED) } \\
\text { [A=C*D] }\end{array}$ & $\begin{array}{c}\text { Teknolojik } \\
\text { Değişim } \\
\text { (TD) } \\
{[\mathrm{B}]}\end{array}$ & $\begin{array}{c}\text { Saf Teknik } \\
\text { Etkinlik } \\
\text { Değişimi } \\
\text { (STED) } \\
\text { [C] }\end{array}$ & $\begin{array}{c}\text { Ölçek } \\
\text { Etkinliği } \\
\text { Değişimi } \\
\text { (ÖED) } \\
{[\mathrm{D=A} \text { ) }]}\end{array}$ & $\begin{array}{c}\text { Toplam } \\
\text { Faktör } \\
\text { Verimliliği } \\
\text { Değişimi } \\
\text { (TFVD) } \\
{[\mathrm{E}=\mathrm{A} * \mathrm{~B}]}\end{array}$ \\
\hline $\mathbf{A}$ & 0,945 & 1,022 & 1,000 & 0,945 & 0,966 \\
\hline $\mathbf{B}$ & 1,039 & 1,025 & 1,000 & 1,039 & 1,065 \\
\hline $\mathbf{C}$ & 1,000 & 0,981 & 1,000 & 1,000 & 0,981 \\
\hline $\mathbf{D}$ & 1,046 & 0,985 & 1,000 & 1,046 & 1,030 \\
\hline $\mathbf{E}$ & 0,957 & 1,029 & 0,976 & 0,980 & 0,984 \\
\hline $\mathbf{F}$ & 0,986 & 1,017 & 0,989 & 0,998 & 1,003 \\
\hline $\mathbf{G}$ & 0,989 & 0,962 & 1,000 & 0,989 & 0,951 \\
\hline $\mathbf{H}$ & 0,973 & 0,923 & 0,992 & 0,980 & 0,897 \\
\hline $\mathbf{I}$ & 0,957 & 1,004 & 1,005 & 0,952 & 0,962 \\
\hline $\mathbf{K}$ & 0,961 & 0,814 & 0,962 & 0,999 & 0,782 \\
\hline $\mathbf{L}$ & 0,988 & 0,989 & 1,000 & 0,988 & 0,977 \\
\hline $\mathbf{M}$ & 1,000 & 1,263 & 1,000 & 1,000 & 1,263 \\
\hline $\mathbf{N}$ & 0,990 & 0,966 & 1,000 & 0,990 & 0,956 \\
\hline Ortalama & $\mathbf{0 , 9 8 7}$ & $\mathbf{0 , 9 9 4}$ & $\mathbf{0 , 9 9 4}$ & $\mathbf{0 , 9 9 2}$ & $\mathbf{0 , 9 8 1}$ \\
\hline & & & & & \\
\hline
\end{tabular}

Analiz sonucunda elde edilen TFVD değeri karar verme birimleri açısından bakıldığında fabrikaların 9'u $(\% 69,2)$ belirlenen dönem itibariyle 1'in altındadır. Tablo-2'ye göre findık fabrikalarında 2006-2012 yılları arasında TFV endeksi ortalama \%1,9 oranında TFV endeksinde azalış olduğu görülmektedir. Bu azalışın \%0,6'sı teknolojik değişimden, \%1,3’ü ise teknik etkinlik oranındaki azalıştan kaynaklanmaktadır. Fabrikalar bazında değerlendirildiğinde ise 13 fındık fabrikasının 4'ü ( B, D, F, M) TFV artışı yaşadığı görülmektedir. M fındık fabrikası \%26,3 artış ile en fazla TFV artışı yaşayan fabrika olmuştur. İkinci sırada \%6,5 artış ile B findık fabrikası yer alırken onu \%3'lük artış ile D fabrikası ve \%0,3 ile F fabrikası izlemektedir. TFV değişimi 1'den küçük olan 9 fındık fabrikası içerisinde K findık fabrikası $(0,782)$ ve $\mathrm{H}$ findık fabrikası $(0,897)$ TFV'si en fazla azalan fabrikalar olmuştur.

Teknik etkinlik kara verme birimleri açısından değerlendirildiğinde findık fabrikalarının 9' unun $(\% 69,2)$ belirlenen dönemde teknik etkinlikteki değişim değeri 1'in altında kalmıştır. 2 fabrikan $(\% 15,4) 1$ 'in üzerinde teknik etkinlik değerine sahiptir. 2 findık fabrikasının ise teknik etkinlik 
değerinde bir değişim olmamıştır. Teknik etkinlik değeri en yüksek olan \%4,6 ile D fabrikası, en düşük olan ise $\% 5,5$ ile $\mathrm{A}$ fabrikası olmuştur.

Teknolojik etkinlikteki değişime bakıldığında 6 fabrikanın (A, B, E, F, I, M) \%46 oranında teknolojik ilerleme gösterdiği görülmektedir. $\mathrm{Bu}$ fabrikalar ilgili dönemde teknolojik gelişme göstererek aynı girdi miktarı ile daha fazla çıktı üretebilmiştir. M fabrikası 1,263 teknolojik değişim skoruyla $(\% 26,3)$ en fazla teknolojik değişim artış1 göstermiştir. Diğer taraftan 7 findık fabrikasında (C, D, G, H, K, L, N) teknolojik değişim skorunda azalma tespit edilmiştir. Bu fabrikalarda teknolojik gerileme nedeniyle ilgili dönemde üretim durumlarında azalma meydana gelmiştir. $\mathrm{K}$ findık fabrikası 0,814 skoru ile ilgili dönemde en fazla $(\% 18,6)$ teknolojik gerileme gösteren karar birimidir.

Karar birimlerinin saf teknik etkinlik değişimi incelendiğinde, 4 findık fabrikası (E, F, H, K) (\%30) 1'in altında saf teknik etkinlik değişim değerine sahiptir. 8 fındık fabrikasında (A, B, C, D,G, L, $\mathrm{M}, \mathrm{N})$ ise herhangi bir artış ya da azalış olmamıştır. I fındık fabrikasının 1,005 skoru ile $(\% 0,5)$ ilgili dönemde saf teknik etkinlik değişiminde artış gösteren tek fabrika olduğu görülmüştür.

Ölçek etkinlik değişiminde 2 fındık fabrikası (B, D) (\%15,3) 1'in üstünde ölçek etkinlik değişimine sahiptir. 9 findık fabrikası (A, E, F, G, H, I, K, L,N) $(\% 69,2) 1$ 'in altında ölçek etkinlik değişimine sahiptir. 2 fındık fabrikasında $(\mathrm{C}, \mathrm{M})$ ise herhangi bir azalış ya da artış olmamıştır. Malmquist-TFV endeksinde yıllar itibariyle yaşanan değişim Tablo-3'te verilmiştir.

\begin{tabular}{|c|c|c|c|c|c|}
\hline \multicolumn{7}{|c|}{ Tablo - 3 Yıllara Göre Analiz Sonuçları } \\
\hline YILLAR & $\begin{array}{c}\text { Teknik } \\
\text { Etkinlik } \\
\text { Değişimi } \\
\text { (TED) } \\
\text { [A=C*D] }\end{array}$ & $\begin{array}{c}\text { Teknolojik } \\
\text { Değişim } \\
\text { (TD) } \\
{[\mathrm{B}]}\end{array}$ & $\begin{array}{c}\text { Saf Teknik } \\
\text { Etkinlik } \\
\text { Değişimi } \\
\text { (STED) } \\
{[\mathrm{C}]}\end{array}$ & $\begin{array}{c}\text { Ölçek } \\
\text { Etkinliği } \\
\text { Değişimi } \\
\text { (ÖED) } \\
{[\mathrm{D}=\mathrm{A} / \mathrm{C}]}\end{array}$ & $\begin{array}{c}\text { Toplam Faktör } \\
\text { Verimliliği } \\
\text { Değişimi } \\
\text { (TFVD) } \\
{[\mathrm{E}=\mathrm{A} \text { *B] }}\end{array}$ \\
\hline 2007 & 0,957 & 0,920 & 0,977 & 0,980 & 0,881 \\
\hline 2008 & 1,005 & 1,205 & 0,984 & 1,021 & 1,211 \\
\hline 2009 & 0,966 & 1,063 & 1,010 & 0,956 & 1,027 \\
\hline 2010 & 1,072 & 0,698 & 1,022 & 1,050 & 0,749 \\
\hline 2011 & 0,949 & 1,097 & 0,954 & 0,995 & 1,041 \\
\hline 2012 & 0,974 & 1,070 & 1,019 & 0,956 & 1,042 \\
\hline Ortalama & $\mathbf{0 , 9 8 7}$ & $\mathbf{0 , 9 9 4}$ & $\mathbf{0 , 9 9 4}$ & $\mathbf{0 , 9 9 2}$ & $\mathbf{0 , 9 8 1}$ \\
\hline
\end{tabular}

Teknik etkinlik değişiminin 2008 ve 2010 yıllarında bir önceki yıllara göre arttığı, 2007, 2009, 2011 ve 2012 yıllarında ise bir önceki yıllara göre azaldığı görülmüştür. Değişim dereceleri incelendiğinde ise 2008 ve 2010 y1llarında sirasıyla \%0,5 ve \%7,2 arttığ1, 2007, 2009, 2011 ve 2012 yıllarında ise sırasıyla $\% 4,3 ; \% 3,4 ; \% 5,1$ ve $\% 2,6$ oranında azalış olduğu görülmüştür. Yııllık teknolojik etkinlik değişiminin ortalamasına bakıldığında ise 13 fabrikanın 2006-2012 yılları arasında $\% 1,3$ oranında azalma olduğu görülmüş̧ür.

Teknolojik değişiminin 2008, 2009, 2011 ve 2012 yıllarında bir önceki yıllara göre arttığ 1 , 2007 ve 2010 yıllarında ise bir önceki yıllara göre azaldığı görülmüștür. 2008, 2009, 2011 ve 2012 yılları sırasıyla $\% 20,5 ; \% 6,3 ; \% 9,7$ ve $\% 7$ oranında artış olmuştur. 2007 ve 2010 yıllarında ise $\% 8$ ve \%30'luk bir azalış olmuştur. Yıllar itibariyle ortalamaya bakıldığında ise \%0,6 oranında bir azalış olduğu görülmüştür. 
TFV'deki değişim yıllar itibariyle bakıldığında 2008, 2009, 2011 ve 2012 yıllarında bir önceki yıllara göre arttığ 1,2007 ve 2010 yıllarında ise bir önceki yıllara göre azaldığ görülmüştür. 2008, 2009, 2011 ve 2012 yılları sırasıyla \%21,1; \%2,7; \%4,1 ve \%4,2 oranında artış olmuştur. 2007 ve 2010 yıllarında ise \%11,9 ve \%25,1'lik bir azalış olmuştur. Yıllar itibariyle ortalamaya bakıldığında ise $\% 1,9$ oranında bir azalma olduğu görülmüştür.

\section{Sonuç ve Öneriler}

Günümüzde rekabetin giderek artması nedeniyle fabrikaların mevcut girdileri ile en fazla çıktıyı elde etmek veya mevcut çıktılarını az girdiyle sağlayabilmek için yoğun bir çaba göstermektedir. Firmalar bulundukları durumu benzer işletmelerle kıyaslamaya başlamıştır. $\mathrm{Bu}$ çalışmada 2006-2012 yılları arasında 13 findık fabrikasının etkinliklerindeki değişimin nedenini belirleyebilmek için Malmquist-TFV Endeksi yöntemi kullanılmıştır.

Malmquist-TFV Endeksi sonuçlarına bakıldığı zaman, ilgili dönemde TFV'nin olumsuz yönde değiştiği tespit edilmiştir. Bu azalışın nedenine bakıldığında, teknik etkinlikte ve teknolojik etkinlikteki azalmalar dikkat çekmektedir. Sonuçta, teknolojik etkinlikte yaşanan gerileme TFV endeksini olumsuz etkilemiş ve azalmaya neden olmuştur. Fabrikalar teknik olarak ve teknolojik olarak etkinsizlerdir. Bu da fabrikaların teknolojik ve teknik açıdan gelişim gösteremedikleri anlamına gelmektedir.

Yıllara göre fabrikaların TFV endeksi sonuçlarına bakıldığında 2008 yılında TFV endeksinde en yüksek artışın yaşandığ 1 görülmektedir. 2008 yılında yaşanan bu artış hem teknolojik değişimden hem de teknik etkinlik değişiminden kaynaklanmaktadır. Ancak bu yılda saf teknik etkinlik değerinin düşük olması teknik etkinlik değerinin azalmasına ve dolayısıyla da TFV endeksinin azalmasına neden olmuştur. Diğer dikkat çeken y1l ise TFV endeksinin en düşük olduğu 2010 y1lıdır. 2010 yılında yaşanan bu azalışın tamamı teknolojik değişimden kaynaklanmakta ve 2006-2012 yılları içerisinde en düşük teknolojik değişim değeri olduğu görülmüştür. Teknolojik alanda yeniliklere gidilirse TFV endeksi artışı daha yüksek oranda olacaktır.

Giresun ilindeki fındık fabrikalarının yarıdan fazlası küçük ölçekli işletmeler niteliğindedir. Bölgedeki iklim şartları findığın kurutulma aşamasında kalitesizliğin önüne geçilebilmesi için yapay kurutma teknolojisinin kurulması gerekmektedir. Ancak fabrikaların sermaye yetersizliğinde dolayı bu durum dikkate alınamamaktadır. Bu fabrikalara yönelik olarak Ar-Ge çalışmalarının artırılması gerekmektedir. Yaşanan ekonomik olumsuzluklardan dolayı birçok fabrika, kapasitelerini küçültmüş ve atıl kapasite ile çalışmak zorunda kalmıştır. Fabrikaların verimliliklerini ancak fabrikaların teknolojik ve teknik altyapısının artırılması ile mümkün olacaktır. Sektörel ve bölgesel teşviklerde bulunulması gerekmektedir.

Sonuç olarak enerji, üretilen malın satılabilmesi, kalitesi, işçi maliyetlerini en uygun hale getirmek için teknolojinin mutlaka takip edilmesi ve yöneticilerin uyguladıkları politikaları ve yöntemleri gözden geçirmesi gerekmektedir.

Giresun'daki 13 findık fabrikasının 2006-2012 yılları arasındaki etkinliğini değerlendirmek için yapılan bu çalışmanın birçok kısıtın olabileceği göz ardı edilmemelidir. Özellikle fındığın kalitesi ve ihracat verileri modele dahil edilememiştir. Çıktılardaki kısıt ise çıktı türünün bir tane olmasıdır. $\mathrm{Bu}$ nedenle fabrikaların etkinlik değişimi değerleri birbirine çok yakın çıkmıştır. Sonuçlar yorumlanırken bu konulara dikkat etmek gerekmektedir. Ayrıca elde edilen sonuçların belirtilen dönemlerde kurulan model için geçerli olduğu, farklı modeller kullanıldığında ise farklı sonuçların oluşabileceği göz ardı edilmemelidir. $\mathrm{Bu}$ çalışmanın yanı sıra gelecekte aynı modelin Türkiye genelindeki findık fabrikalarına uygulanması ve bu çalışmada eksik olan kısıtlarında modele ilave edilerek geliştirilmesi, fabrikaların bölgesel olarak ayrıştırılarak etkinliklerinin sonuçları incelenebilir. 


\section{KAYNAKÇA}

Aktan, H.E. ve Tosun Ö.,(2010), "SSK hastanelerinin Sağlık Bakanlı̆̆ı'na devrinin hastane verimlilikleri üzerindeki etkileri", Tisk Akedemijavascript: doLinkPostBack(",'ss\%7E\%7EJN \%22TISK AKADEMI\%22\%7C\%7Cs|\%7E\%7Erl',"'); 5(10), 112-129.

Ar, İ.M., Baki, B. (2009), “ Çaykur’ a Bağlı Fabrikaların Etkinliklerinin Ölçülmesi “, İktisat İşletme ve Finans, 24(284), 3-18.

Arcelus, F. J., and Arozena, P., (1999), "Measuring Sectoral Productivity Across Time and Across Countries", European Journal of Operational Research, 119, 254-266.

Avcı, M. A ve Kaya, A (2008), "Geçiş Ekonomileri ve Türk Tarım Sektöründe Etkinlik ve Toplam Faktör Verimliliği Analizi (1992- 2004)”, Ege Akademik Bakış, 8(2), 843-860.

Banker, Rajiv D., Charnes, A., and Cooper, W.W. (1984), "Some Models for Estimating Technical and Scale Inefficiencies in Data Envelopment Analysis", Management Science, 30 (9), 10781092.

Boussofiance, A., Dyson, R., and Rhodes, E.(1991), “Applied Data Envelopment Analysis", European Journal of Operational Research, 2(6), 1-15.

Bozdağ, Emre G., (2007), Şeker Sanayinde İktisadi Etkinlik: Avrupa Birliği-Türkiye Karşılaştırılması, Yayımlanmamış Doktora Tezi, Gazi Üniversitesi Sosyal Bilimler Enstitüsü.

Candemir, M ve Deliktaş, E. (2006), “TİGEM işletmelerinde Teknik Etkinlik, Ölçek Etkinliği, Teknik İlerleme, Etkinlikteki Değişme ve Verimlilik Analizi: 1999- 2003”, Ankara, Tarım ve Köyişleri Bakanlı̆̆ı Tarımsal Ekonomi Araştırma Enstitüsü (Yayın No: 141).

Candemir, M., Özcan, M., Güneş, M., Deliktaş, E., (2011), "Technical Efficiency and Total Factor Productivity Growth in The Hazelnut Agricultural Sales Cooperatives Unions in Turkey", Mathematical and Computational Applications, 16(1), 66-67.

Chen, Y.A. (2003), “ Non-Radical Malmquist Productivity Index With an Illustrative To Chinese Major Industries", International Journal of Production Economics. 83(1), 27-35.

Charnes, A., Cooper and Rhodes, W. (1978), “ Measuring the Efficiency of Decision Making Units.” European Journal of Operational Research, 2, 429-444.

Cingi, S. ve Tarım, A.,(2000), “Türk Banka Sisteminde Performans Ölçümü DEA- Malmquist TFP Endeksi Uygulaması”, Türkiye Bankalar Birliliği Araştırma Tebliğleri serisi, 2000-01.

Coelli, T.J. and Rao, D.S.P. (2003), "Total Factor Productivity Growth in Agriculture: A Malmquist Index Analysis of 93 Countries, 1980-2000", Agricultural Economics, 32, 115-134.

Çakır, S., (2011). “ Kamu Şeker Fabrikalarında Etkinlik Ölçümü: Bir VZA ve Malmquist TFV Uygulaması”, Karadeniz Teknik Üniversitesi Sosyal Bilimler Enstitüsü, Yayınlanmamış Yüksek Lisans Tezi.

Dağ, S., (2011), “Türkiye'deki Katılım ve Mevduat Bankalarının etkinlikleri”, Dumlupınar Üniversitesi Sosyal Bilimler Enstitüsü, Yayınlanmamış Yüksek Lisans Tezi.

Deliktaş, E. (2002), “Türkiye özel sektör imalat sanayinde etkinlik ve Toplam Faktör verimliliği analizi”, ODTU Dergisi, 3(4), 247-284.

Demirci, S. (2001), "Şeker Fabrikalarının Performans Analizi ve Toplam Faktör Verimliliklerinin Ölçümü: DEA ve Malmquist Indeks Yaklaşımı”, Tarım ve Köyişleri Bakanlığı Tarımsal Ekonomi Araştırma Enstitüsü, Ankara, 67.

Demirci, S., (2003), "Şeker Kanunundaki Değişiklikle Olası Etkilerin Ekonomik Analizi”, Tarımsal Ekonomi Araştırma Enstitüsü Yayınları. Ankara, 102. 
Dinçer, S.E., (2008), "2005-2006 döneminde IMKB uygulaması", Marmara Üniversitesi, İ.İ.B.F. Dergisi, 25(2), 824-846.

Donthu, N., Hershberger, E. K., and Osmonbekov, T. (2005), "Benchmarking Marketing Productivity Using Data Envelopment Analysis", Journal of Business Research. 58(11), 1474-1482.

Fare, R., Grosskopf, S., Norris, M., and Zhang, Z. (1994), "Productivity Growth, Technical Progress, and Efficiency Change in Industrialized Countries", The American Economic Review, 84 (1), 66-83.

Guan J.C., Yam R.C.M., Mok, C.K., and Ma, N. (2006), “ A Study of the Relationship Between Competitiveness and Technological Innovation Capability Based on DEA Models", Europen Journal of Operational Research. 170(3), 971-986.

Gümrük ve Ticaret Bakanlığı Kooperatifçilik Genel Müdürlüğü 2012 Yılı Findık Raporu,2013, http://koop.gtb.gov.tr/data/51f7a45f487c8e14b4454603/2012\%20Y\%C4\%B11\%C4\%B1\%20F \%C4\%B1nd\%C4\%B1k\%20Raporu.pdf [10. 05. 2014].

Işik, I. Ve Hassan, M.K., (2003), "Financial disruption and bank productivity. The 1994 experience of Turkish banks", The Quarterly Review of Economics and Finance, 43, 291-320.

Kayalı C., A.,(2007), "Türkiye'de faaliyet gösteren sigorta şirketlerinin 2000-2006 dönemindeki etkinlik analizi”, Celal Bayar Üniversitesi I.I.I.B.F., 14(2), 103-115.

Kesbiç, C.Y., Tokatlığlu, İ., ve Ürüt, S., (2004), "Rekabet gücü göstergeleri; Türk sanayi için VZAMalmquist TFV Endeksi uygulaması", İktisat İsletme ve Finans dergisi, 19(220), 63-75.

K1lıç, O., Ceyhan, V., Alkan, I., (2009), "Determinants of Economic Efficiency: a Case Study of Hazelnut (Corylus avellana) Farms in Samsun Province, Turkey", New Zealand Journal of Crop and Horticultural Science, 37, 263-270.

Kula, V., Kandemir, T. ve Özdemir, L.,(2009), "IMKB' ye Koteli Çimento şirketleri üzerine bir araştırma", Afyon Kocatepe Üniversitesi İ.I. B.F., 11(17), 187-202.

Kutlar, A., Bakırcı, F. ve Yüksel, F., (2010), "Endeksle Etkinlik Ölçümü:Belediyeler Üzerine Bir Uygulama", Bilgi Dergisi, 12(1), 20.

Küçükşimşek, M., (2004), “1999-2003 döneminde Türkiye'deki ortaöğretim kurumlarının ÖSS'deki etkinliklerinin DEA-Malmquist TFP endeksi ile incelenmesi”, Gazi Üniversitesi Fen Bilimleri Enstitüsü, Yayınlanmamış Yüksek Lisans Tezi.

Lorcu, F., (2010), "Malmquist Toplam Faktör Verimlilik Endeksi: Türk Otomotiv Sanayi Uygulaması”, İstanbul Üniversitesi Işsletme Fakültesi Dergisi, 39 (2), 276-289.

Mollavelioğlu, M. Ş., (2009), "Sürdürülebilir Tarımın Ölçümü ve Türkiye açısından Değerlendirilmesi”, Hacettepe Üniversitesi, Sosyal Bilimler Enstitüsü, Yayınlanmamış Doktora Tezi.

Öncü, S. ve Aktaş, R., (2007), "Yeniden Yapılandırma Döneminde Türk Bankacılık Sektöründe Verimlilik Değişimi”, Celal Bayar Üniversitesi I.I.I.B.F., 14(1), 247-266.

Özok, U., (2006), “Türkiye'deki İllerin Tarım Etkinliklerinin İncelenmesi: Bir VZA ve Malmquist TFV uygulaması", Gazi Üniversitesi Fen Bilimleri Enstitüsü, Yayınlanmamış Yüksek Lisans Tezi.

Perçin, S. ve Ustasüleyman, T., (2007), “ Tekstil ve Gıda sektöründe Etkinlik ölçümü: VZAMalmquist TFV Endeksi uygulaması”, İktisat İsletme ve Finans, 22(250), 154-171.

Raheman, A., Qayyum, A., and Afza, T., (2009), "Efficiency Dynamics of Sugar Industry in Pakistan", Pakistan Development Review, 48 (4), 921-938.

Sevim, C., (2006), “Avrupa Birliğine Uyum Sürecinde Türk Tarımının Yapısı, Tarım Politikaları ve etkinlik karşılaştırması", Gazi Üniversitesi Sosyal Bilimler Enstitüsü, Yayınlanmamış Yüksek Lisans Tezi. 
Sülkü, N.S., (2011), "Performansa Dayalı Ek Ödeme Sisteminin Kamu Hastanelerinin Verimliliği Üzerine Etkileri”, Maliye Dergisi, 160, 242-268.

Şahin, İ., (2009), “Sağlık Bakanlığı’na Devredilen SSK Hastanelerinin Teknik Etkinliği ve Toplam Faktör Verimliliği Analizi”, İktisat işletme ve Finans dergisi, 24(283), 9-40.

Tarım, A. (2001), "Veri Zarflama Analizi: Matematiksel Programlama Tabanlı Göreli Etkinlik Ölçümü Yaklaşımı”, T.C. Sayıştay Başkanlığı Yayınları, No:15, Ankara.

TÜİK, (2011), http://www.tuik.gov.tr. [15.04.2014]

Zaim, O., ve Taşkın, F, (1997), "The Comparative Performance of the Public Enterprise Sector in Turkey: A Malmquist Productivity Index Approach", Journal of Comparative Economics, 25(2), 129-157. 